\title{
Design of Unmanned Underwater Vehicle as Observation Facility Using Computational Fluid Dynamics Analysis
}

\author{
Bagiyo Suwasono, Ali Munazid, Didik Hardianto \\ Department of Naval Architecture and Shipbuilding Engineering, Hang Tuah University, Surabaya, Indonesia \\ bagiyo.suwasono@hangtuah.ac.id; ali.munazid@hangtuah.ac.id;didik.hardianto@hangtuah.ac.id
}

\begin{abstract}
Unmanned Underwater Vehicle (UUV) technology that still developing at this time allowing underwater observation with unmanned vehicle. The challenge in designing a UUV is how the UUV can dive and float with wings (airfoil) as a diving system that gives capability to dive (diving plan) and operates as planned, where the capabilities airfoil shape depending on the flip angle and UUV velocity. The design formula is how to design a wing UUV model as a dive system for underwater observation. The final results of UUV design can dive a maximum of 0.941 meters with the weight and components of 4.36 kilograms.

Keywords: airfoil; lift coefficient; drag coefficient; diving force
\end{abstract}

DOI: $10.7176 / \mathrm{ISDE} / 10-7-01$

Publication date: December $31^{\text {st }} 2019$

\section{Introduction}

Unmanned Underwater Vehicle (UUV) is an operating unmanned vehicle under water surface (submarine). Unmanned is defined, the operator that control the vehicle is not inside the vessel, but the control of the vessel is off-shore (remote control). The development and use of unmanned vehicles is dominated for military and research activities. The activities of oceanographers in oceanographic observation (ocean expedition) are activities to observe and study about oceanography such as temperature, currents, rocks, corals, soil, waves, flora $\&$ fauna etc. Currently oceanographic observation is done by direct survey.

Underwater observation activities are oceanographic observations full with risks and accidents, where the observations are made by diving into the seabed with the help of some seabed survey tools. With the advancements in technology and unmanned systems currently under way, oceanographic observations can be represented by an unmanned underwater vehicle, with that vessel, oceanographers seamlessly assisted in oceanographic observations.

\section{Airfoil}

The application of the Bernoulli law and the Coanda effect. According to Coanda, the flow of fluid through the curved surface will flow along the surface of the arch. Interaction fluid flow with curved surfaces will arise variations of speed and pressure along the top and bottom surfaces as well as the front and rear. The difference in pressure between the top and bottom surfaces results in a resultant force that is perpendicular to the direction of fluid flow, this force is called the lift force while the pressure difference between the front and the back results in a directional force in the direction of the flow of fluid, this style is called a drag force (Tupper, 2004; Katz, 2010).

According to Isaac Newton in Newton III's law of action and reaction. Benjamin Crowell in his book "Newtonian Physics" states that "when an object $X$ gives a force to an object $Y$, then object $Y$ will give the same force to object X". By applying Newton's law III in aerodynamic studies on airfoils, when the airfoil position forms an angle, the fluid that hits the airfoil surface and gives an upward force, the magnitude of the force of the fluid will be converted to an upward force and inhibitory force. 

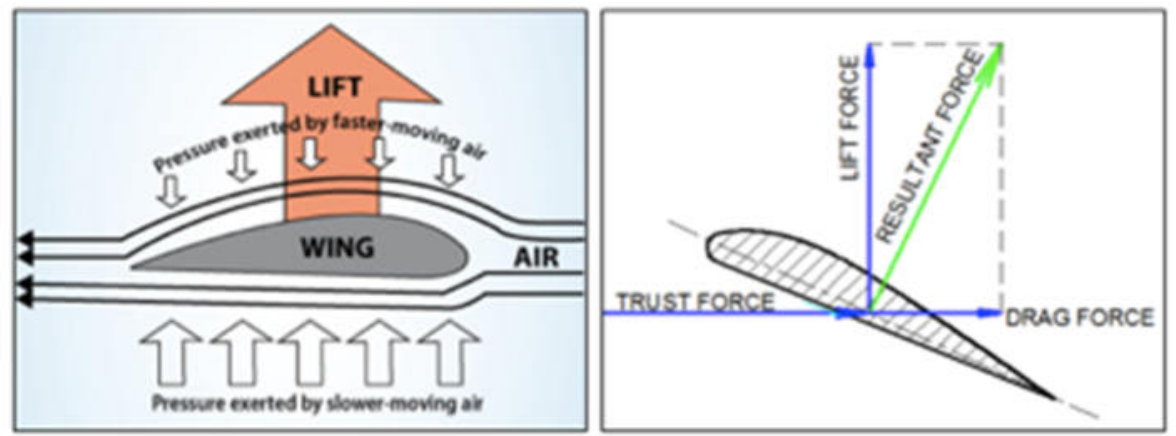

Fig. 1 Bernoulli's Law and Newton's Law III on Airfoil

Application of airfoil mounting in a submarine as a downward force (diving plan) in general can be done. The magnitude of the ability to reach the depth of the dive from the airfoil mount as the dive wing is influenced by the dimensions of airfoil, the flip angle and the speed of the submarine, the greater the dimensions, the flip angle, and the submarine speed, the greater the dive ability of the submarine (Munazid \& Suwasono, 2015).

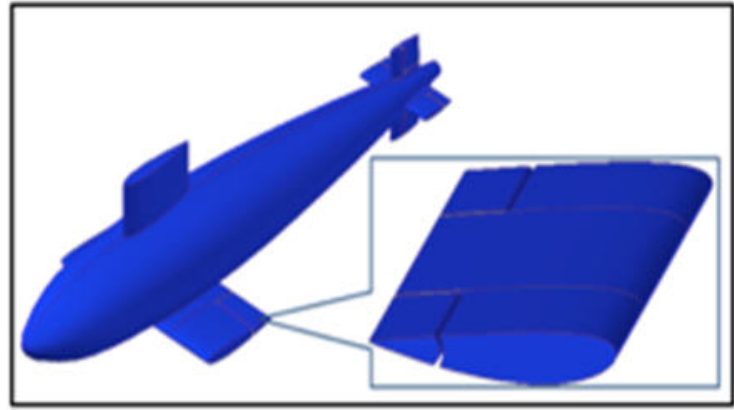

Fig. 2a An Airfoil on UUV

Source: Munazid \& Suwasono, 2015

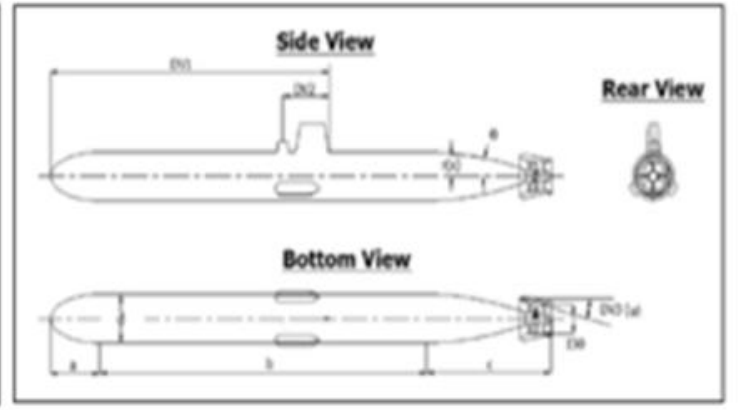

Fig. 2b A Conceptual Design of AUV

Source: Joung et all, 2012

By applying Bernoulli's legal principle, Newton-III's law, and the concept of an airfoil diving system, a vessel planner's challenge in designing an unmanned vessel as a means of underwater scientific observation is how to design a submarine model with a diving method that applies airfoil as a wing that provides a dive style, which is able to dive under the observation tool for underwater observation.

\section{Material and Method}

Considering that the research of unmanned submarines that capable to dive underwater with wing methods as an underwater observation is an experimental study. For that purpose, the design of the submarine first, the design of results is modelled using Ansys software, designing and modelling activities done in the simulation and modelling laboratory. With such modelling, the submarine's performance is seen as expected, especially the UUV diving capability.

The design of research activities is generally grouped in 4 stages as follows:

1. Preparation is an activity that produces data and information needed in the next design, by conducting literature studies and data collection for example. Study airfoil literature, collect technical data components etc.

2. Aerodynamics study is an activity to analysis and obtain information about the characteristics of airfoil, by modelling the airfoil numeric used to obtain the characteristics of airfoil.

3. The design of layout planning, submarine form, submarine characteristics and numerical modelling to know the diving system and the magnitude of inhibitory that occurred in the submarine.

4. The numerical study of ship design by using Ansys Software to obtain ship diving characteristics. 
The research method of designing Unmanned Underwater Vehicle (UUV) as a means of underwater observation is as follows:

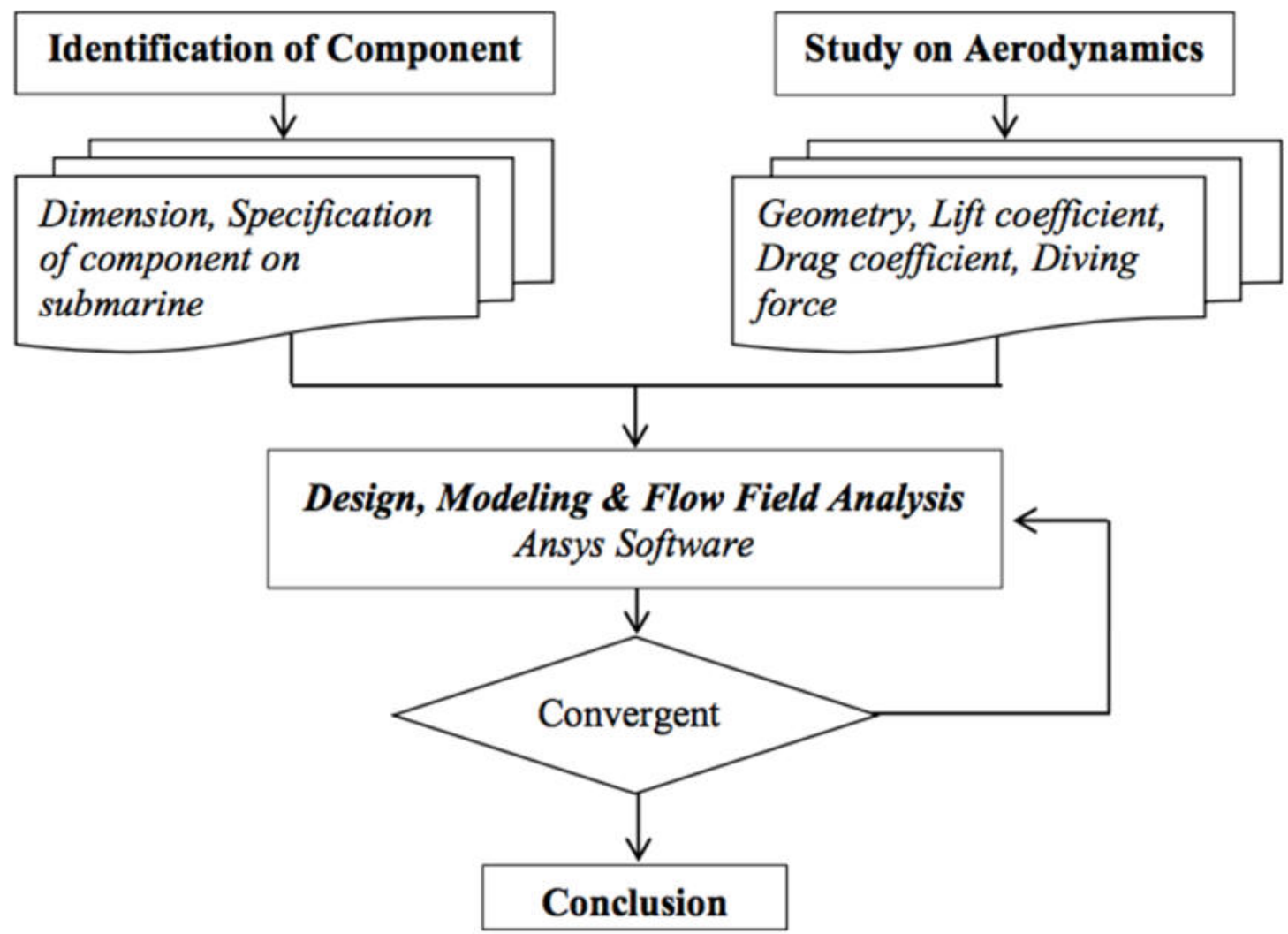

Fig. 3 A Conceptual Framework

\section{Result and Discussion}

\subsection{Components}

1. Accumulator

Accumulator (battery) is a tool that serves to store electrical energy in the form of chemical, accumulator, in addition to storing electricity also supplies electrical energy.

Table 1 Specification of Accumulator

\begin{tabular}{|l|l|}
\hline Capacity & 6 Ah $(10$ jam $)$ \\
\hline Acid Volume & 1 Liter \\
\hline Charge Current & 0.4 Ampere \\
\hline Terminal Type & 5 \\
\hline Size $($ LxBxT $) /$ Weight & $(113 \times 70 \times 85 \mathrm{~mm}) / 1.6$ kilograms \\
\hline
\end{tabular}

2. Electronic Speed Control (ESC)

Electronic Speed Control (ESC) is an electronic circuit functioning as a motor rotation speed control on RC (Remote Control), how to translate the receiver signal from the transmitter.

Table 2 Specification of ESC

\begin{tabular}{|l|l|}
\hline Constant Current & 120 Ampere \\
\hline Burst Current & 240 Ampere \\
\hline Battery & $2-65$ Lippo \\
\hline BEC & 3 Ampere $/ 6$ Volt \\
\hline Size $($ LxBxT) / Weight & $94 \times 33 \times 18 \mathrm{~mm} / 105$ grams \\
\hline
\end{tabular}


3. Electric Motor

Electric motors are electromagnetic devices that converting electrical energy into mechanical energy, i.e. rotary energy used to rotate ship propellers.

Table 3 Specification of Electric Motor

\begin{tabular}{|l|l|}
\hline Power & $2200 \mathrm{kV}$ \\
\hline Max (Ampere) & 4 Ampere \\
\hline Max (Voltage) & 21.2 Voltage \\
\hline Max. Power / RPM & 27 Watt / 2800 RPM \\
\hline Diameter/Length & $40 \mathrm{~mm} / 74 \mathrm{~mm}$ \\
\hline Load Current / Weight & $60 / 378$ grams \\
\hline
\end{tabular}

4. Servo Motor

Servo motor consists of DC motor, gear circuit, potentiometer and control circuit.

Table 4 Specification of Servo Motor

\begin{tabular}{|l|l|}
\hline Operating Voltage & $4.8-6.6$ DC Volt \\
\hline Speed / Torque & 0.16 second $(6.6$ Volt $/ 20 \mathrm{~kg} . \mathrm{cm}$ \\
\hline Size $($ LxBxT)/ Weight & $40.7 \times 20.5 \times 39.5(\mathrm{~mm}) / 0.010$ kilograms \\
\hline
\end{tabular}

\subsection{NACA Series 2414}

The foil used in the design is the NACA Series 2414 foil as follows:
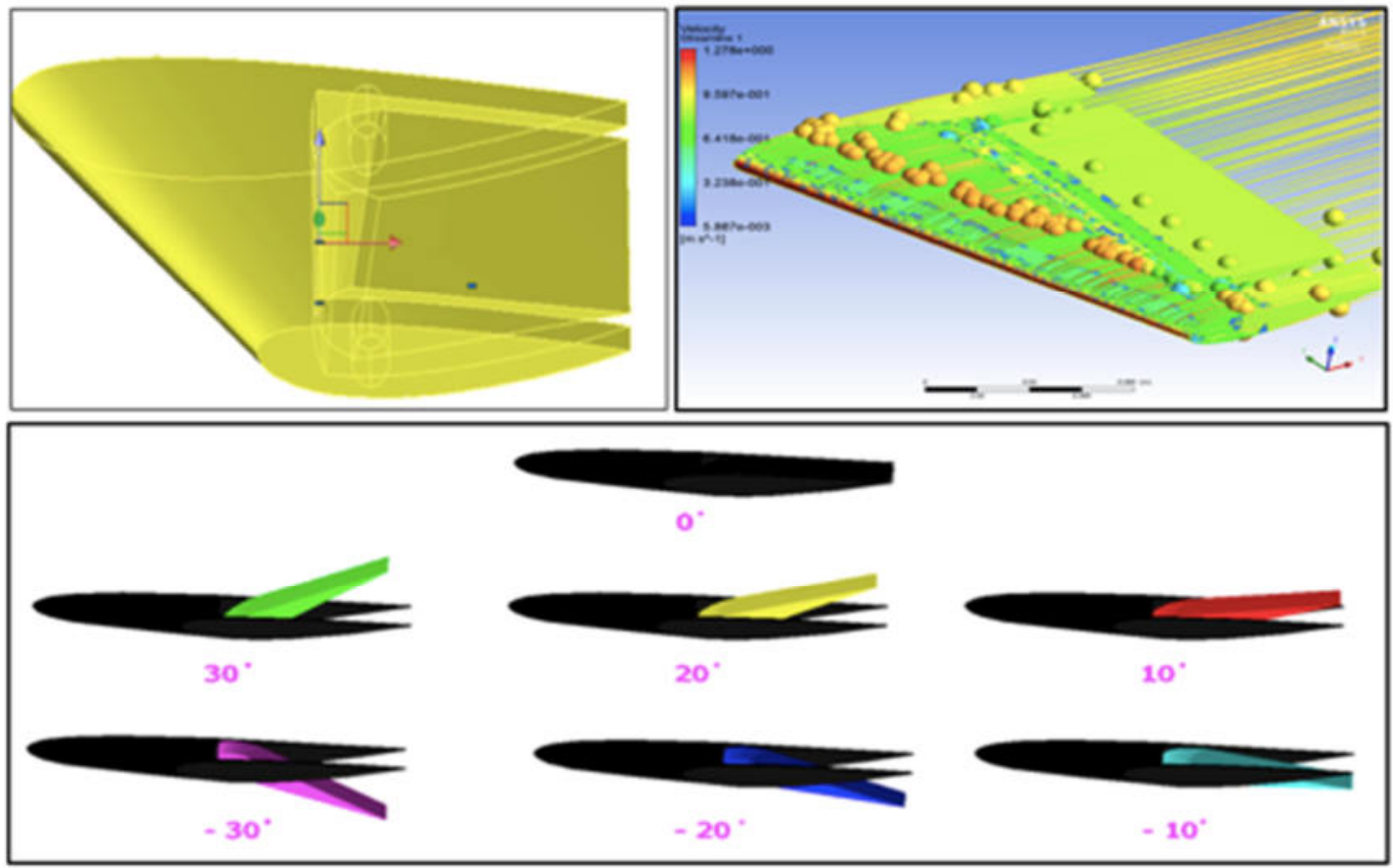

Fig. 4 3D Foil of NACA Series 2414

Result of numerical modelling simulation obtained coefficient of lift. The magnitude of the Lift coefficient value shows that in angle of attack $0^{0}-30^{0}$ is minus, this means that there is a downward force which causes the submarine to move down (dive). The other way for angle $10^{\circ}-30^{\circ}$, foil gives upward force because the Lift coefficient is positive. 


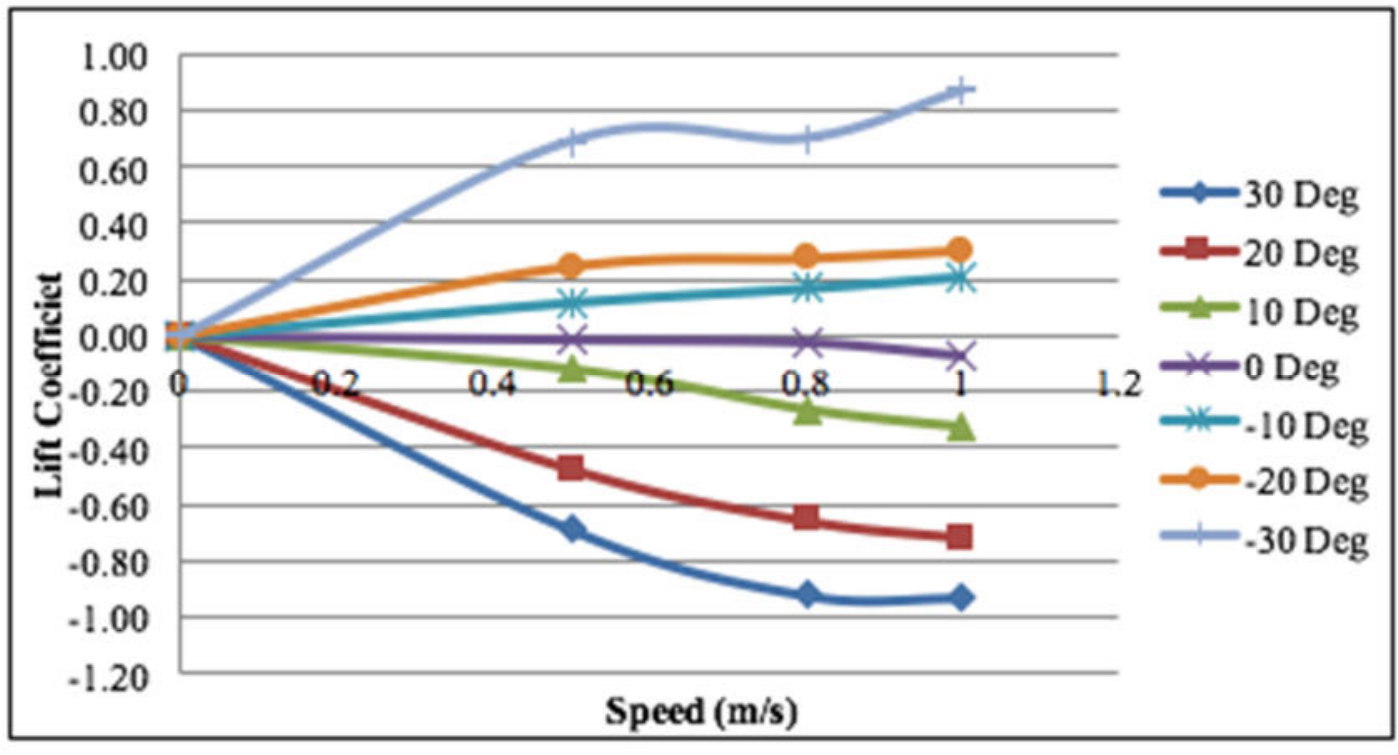

5 Lift coefficient NACA Series 2414 each Angle of Attack

\subsection{Conceptual Design}

1. Layout System

Layout vessel system is a description of the arrangement of existing components in the ship and the picture of electricity. Lay out system in vessel are as follows:

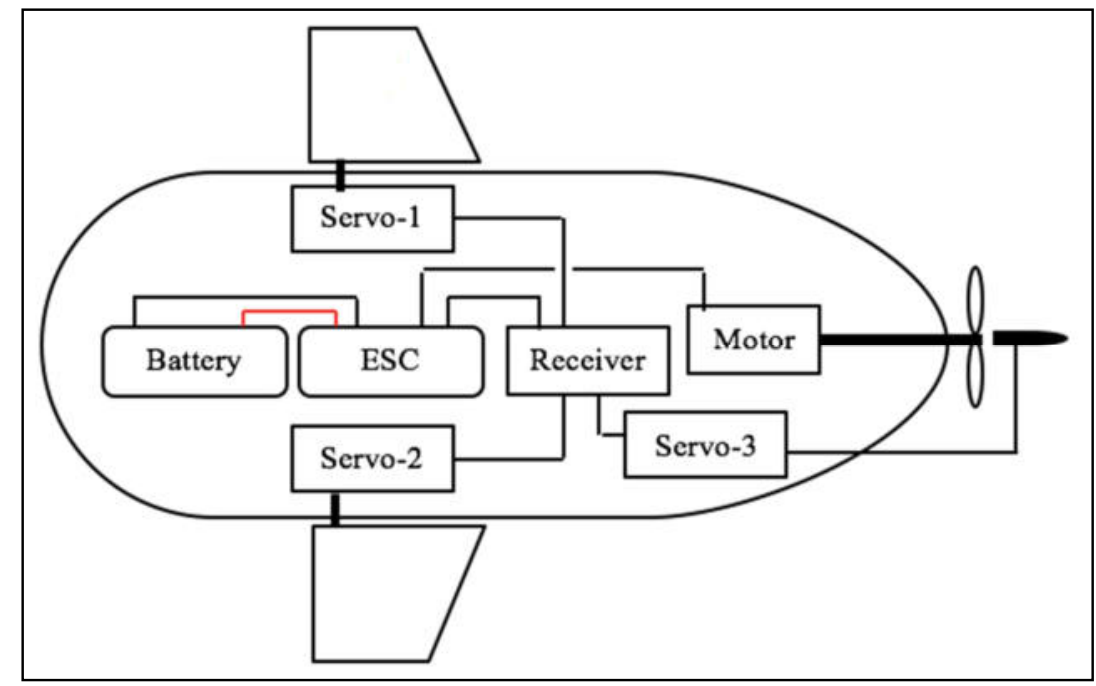

Fig. 6 Layout System

2. Displacement

The Displacement is the weight of water displaced by the volume of water-drowned / buoyant objects of the UUV. UUV displacement of $4.365 \mathrm{~kg}$. 
Table 5. Calculation of Weight

\begin{tabular}{|c|l|c|}
\hline No & \multicolumn{1}{|c|}{ Component } & Weight (kg) \\
\hline 1 & Hull & 2.000 \\
\hline 2 & Motor & 0.378 \\
\hline 3 & Battery (2 unit) & 1.712 \\
\hline 4 & ESC & 0.105 \\
\hline 5 & Servo -1 & 0.010 \\
\hline 6 & Servo -2 & 0.010 \\
\hline 7 & Servo -3 & 0.010 \\
\hline 8 & Receiver & 0.010 \\
\hline 9 & Shaft and Propeller & 0.130 \\
\hline \multicolumn{2}{|c|}{ Total } & $\mathbf{4 . 3 6 5}$ \\
\hline
\end{tabular}

3. Power

The component power installed on the UUV is as follows:

Table 6. Consumption of Power

\begin{tabular}{|c|l|c|c|c|}
\hline No & Component & V (Volt) & I (Ampere) & Power (Watt) \\
\hline 1 & Motor & 21.100 & 4.000 & 84.800 \\
\hline 2 & ESC & 6.000 & 3.000 & 18.000 \\
\hline 3 & Servo -1 & 6.600 & 3.000 & 19.800 \\
\hline 4 & Servo -2 & 6.600 & 3.000 & 19.800 \\
\hline 5 & Servo -3 & 6.600 & 3.000 & 19.800 \\
\hline 6 & Receiver & 5.000 & 3.000 & 15.000 \\
\hline \multicolumn{2}{|r|}{} \\
\hline
\end{tabular}

4. Accumulator

Voltage of 12 Volts and a current of $6 \mathrm{Ah}$, the magnitude of current and duration of operation of the component in the UUV is:

$$
\begin{aligned}
& I=\frac{P}{V} \\
& I=\frac{155,6}{24}=6.48 \simeq 6.5 \text { Ampere }
\end{aligned}
$$

The length of time the submarine operation is

$$
\begin{aligned}
& t=\frac{C}{I}-(20 \%) \\
& t=\frac{12}{6.5}-(0.369)=1.47 \text { hours }
\end{aligned}
$$

5. Planning of Body

With the help of CAD and some software supporting the design of the ship got the following design drawings: 

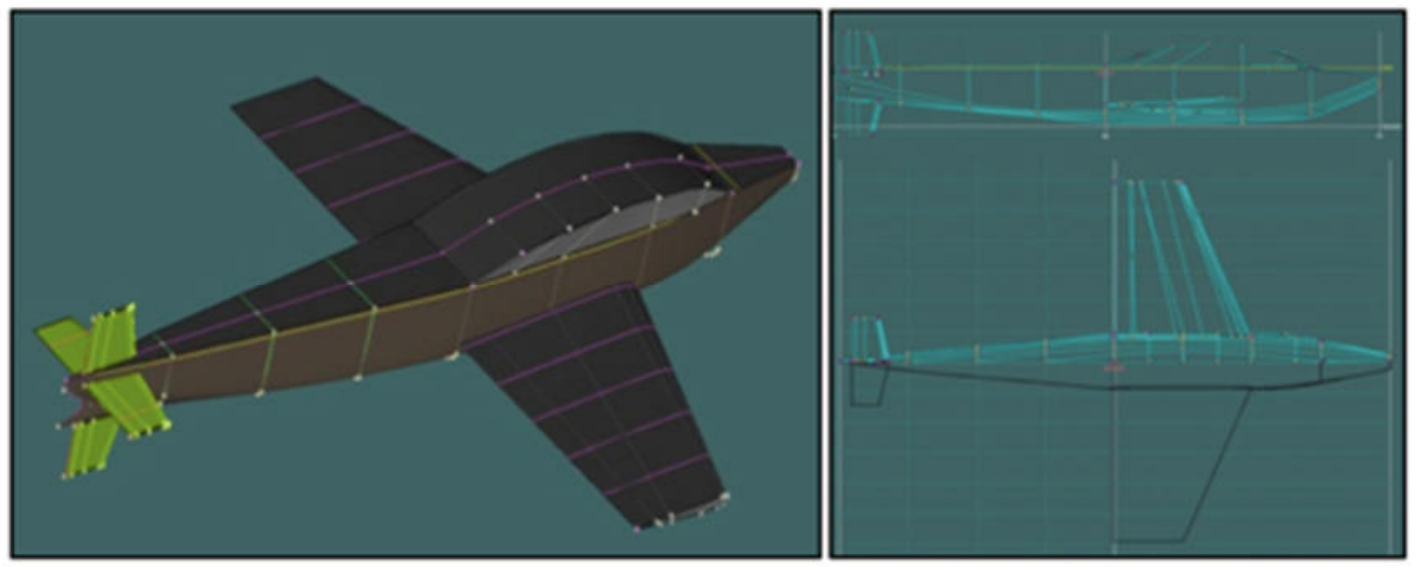

Fig. 7 UUV Body Shape

And obtained the main size of the UUV is:

Table 7. Principle Dimension

\begin{tabular}{|l|l|}
\hline Displacement $(\Delta)$ & 4.36782 kilograms \\
\hline Volume of displacement $(\mathrm{V})$ & $0.00436 \mathrm{~m}^{3}$ \\
\hline Length $(\mathrm{L})$ & 0.80000 meters \\
\hline Breadth $(\mathrm{B})$ & 0.10000 meters \\
\hline Draught $\left(\mathrm{T}_{\mathrm{a}}\right)$ & 0.09000 meters \\
\hline Coefficient of block $(\mathrm{Cb})$ & 0.60600 \\
\hline
\end{tabular}

Correction to the weight of UUV components and initial empty vessel weight / demand:

$\mathrm{V}_{\text {calculate }}=\mathrm{V}_{\text {simulation }}$

4.365 kilograms $=4.36782$ kilograms

The difference from the initial planning $+0.06 \%$, because $0.1 \%$ smaller then allowed.

\subsection{Modelling and Simulation on UUV}

1. Model

From the results of modelling obtained the amount of Lift coefficient and Drag coefficient from submarine.
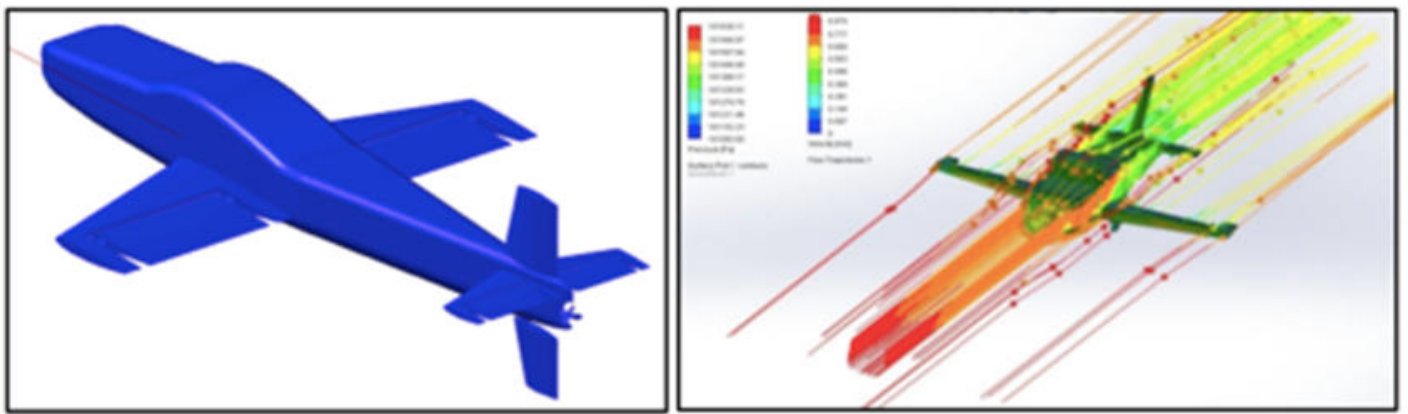

Fig. 8 3D Modelling and Simulation

2. Lift and Drag Coefficient

The result of simulation model from UUV model by using Ansys Software, got the amount of Lift and Drag coefficient. The magnitude of Lift and Drag coefficient as follows: 

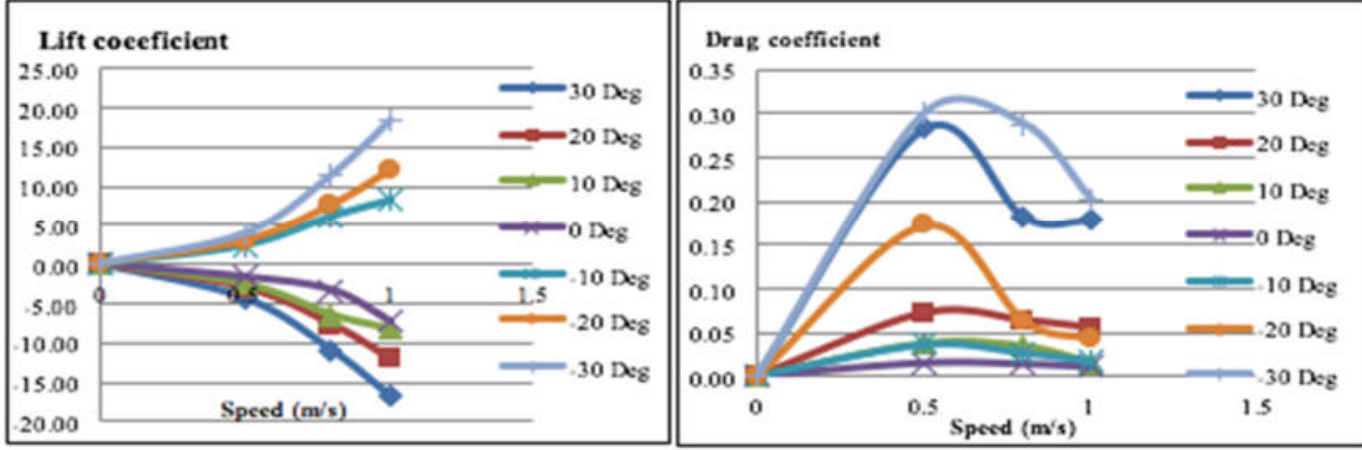

Fig. 9 Lift and Drag Coefficient

3. Diving and Drag Force

Diving Force is a force that occurs due to foil/wings passing through the fluid flow, the force gives the force up and down

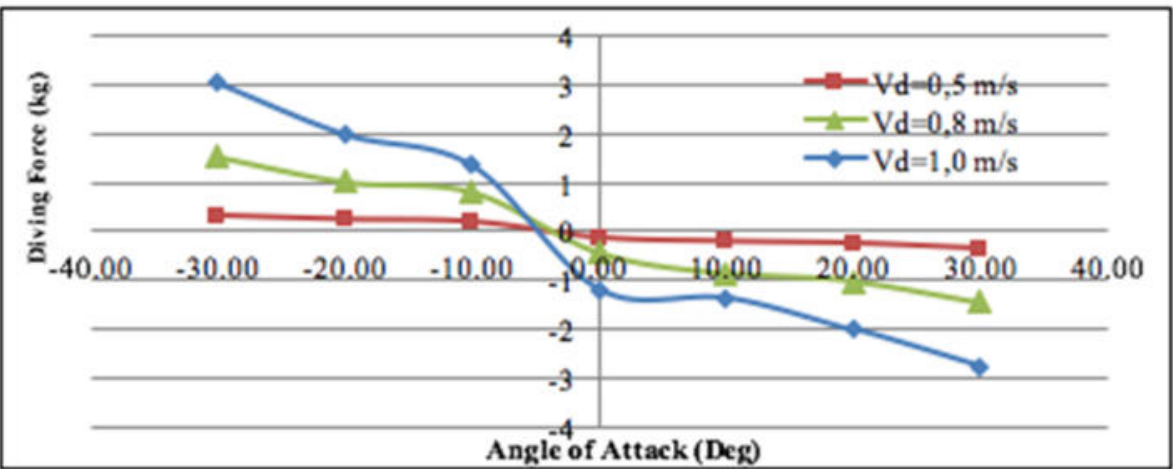

Fig. 10 Diving Force

From the results of modelling and simulation of UUV models obtained drag force as follows:

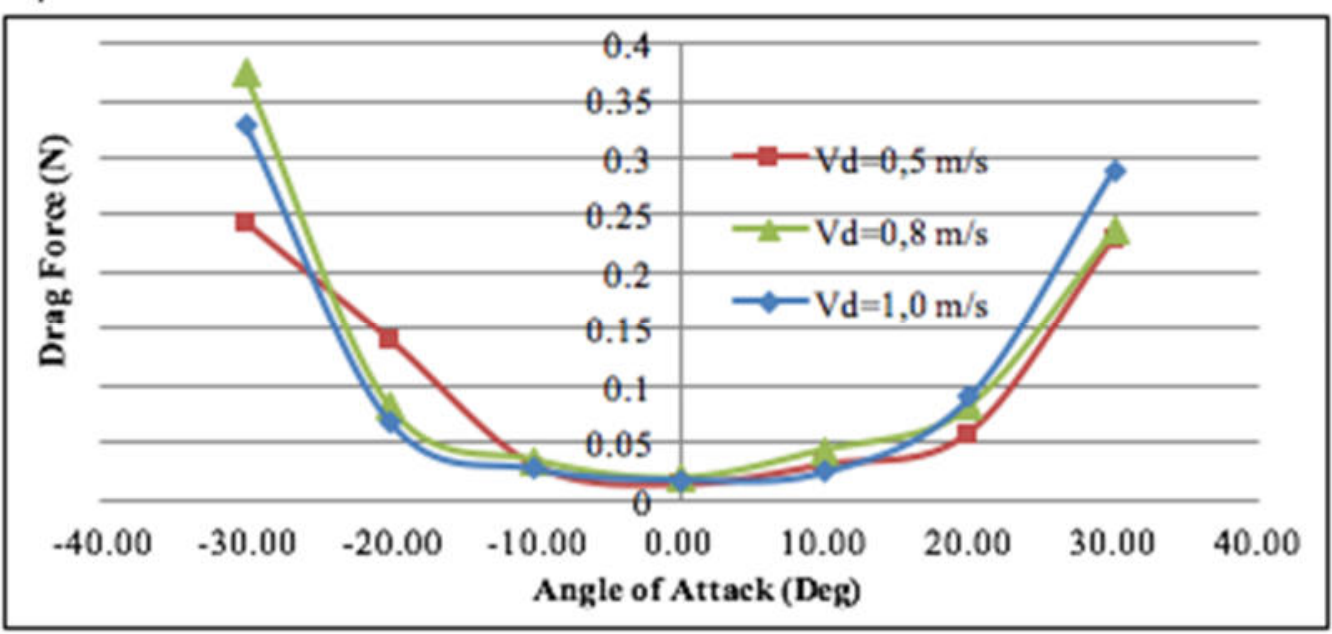

Fig. 11 Drag Force

\subsection{Forces on UUV}

The forces acting on a vertical UUV are: 1 . The ship's weight is equal to the weight of the ship and the component (W), 2. The buoyancy equals the total sinking volume of the ship $\left(\Delta_{\mathrm{S}}\right)$, and 3 . Diving Force is the magnitude of the force resulting from the interaction of the wing/wing with water (D). 


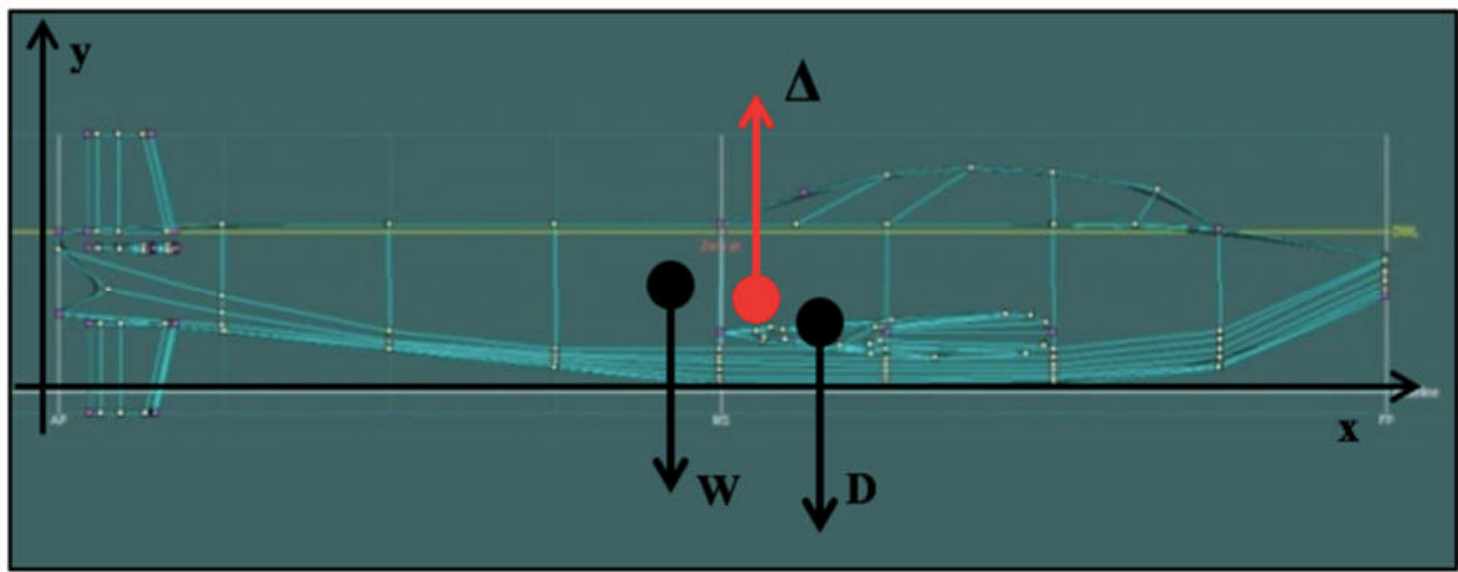

Fig. 12 Forces on UUV

If the number of forces that work is negative then the UUV moves down (dive) or if the upward force $(\Delta)$ $<$ downward force $(F=W+D)$, then the UUV will dive or move downwards. The greater the F force that occurs the deeper the UUV's dive capabilities, the UUV's ability to use the wings/foils as the dive system is influenced by the speed of the UUV and the angle of the foil, the greater the speed and the foil angle, the deeper the capability of the UUV. If the magnitude of the upward force is the same as the down force, it is due to the weight of the ship with the magnitude of the airfoil force, by connecting the UUV's buoyancy to each depth and the magnitude of the force due to the airfoil interaction at every speed and dihedral angle.

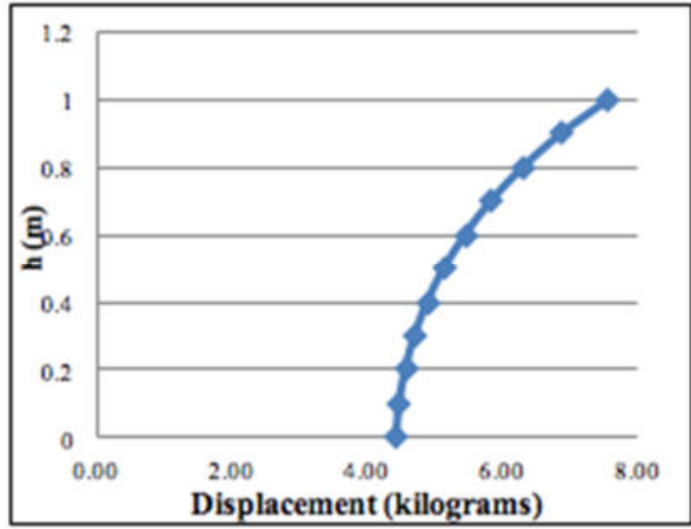

Fig. 13a Relation on Displacement and Depth

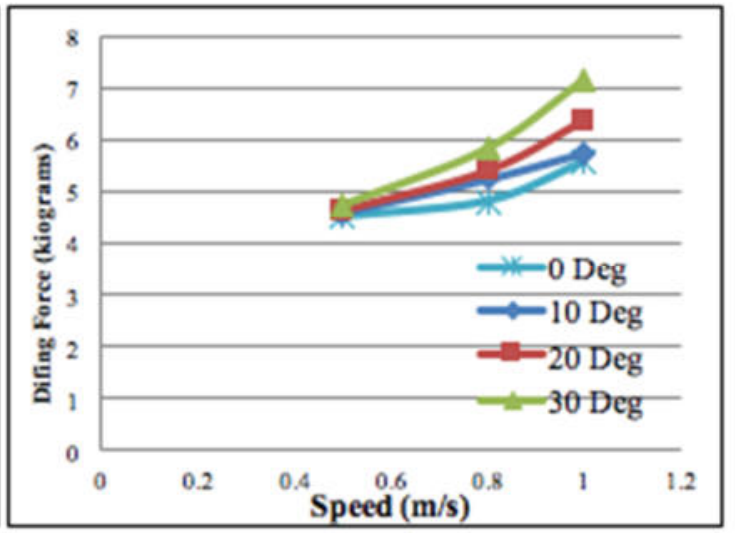

Fig. 13b Relation on Speed and Diving 


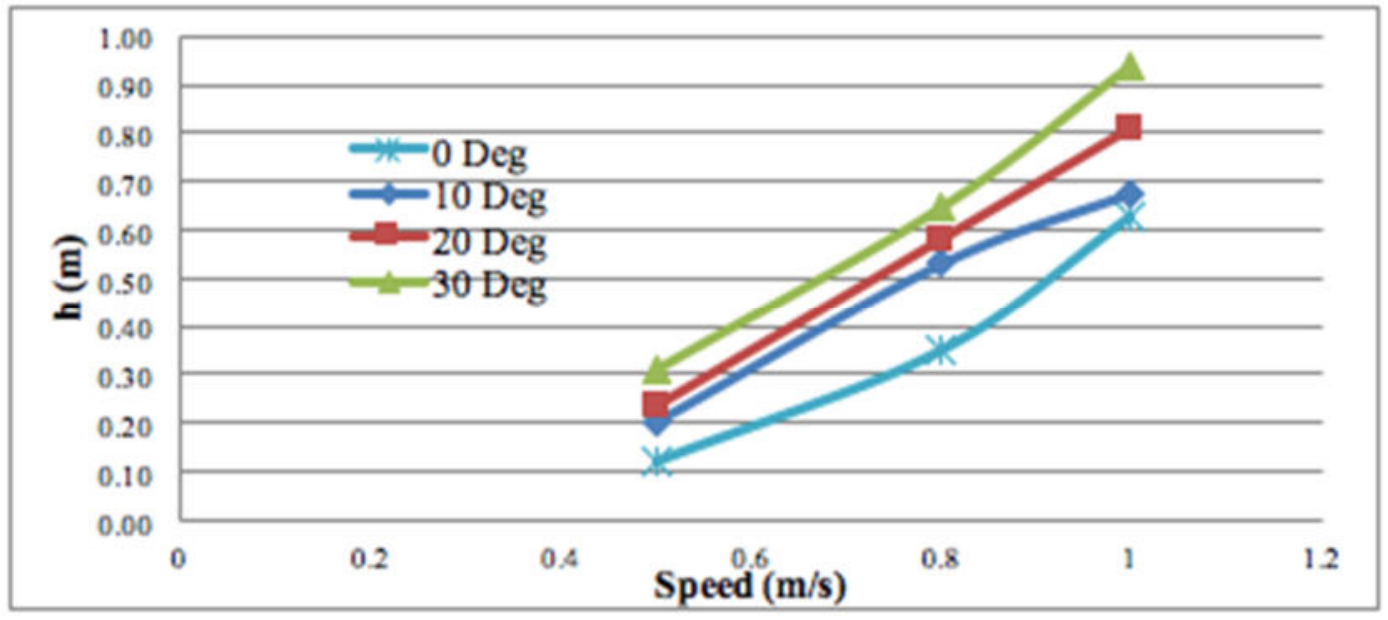

14 Relation between Speed and Depth

Fig.

\section{Conclusion}

The design of a UUV with airfoil system as a wing that produces diving force as a diving plane. Results of Displacement: 4.36 kilograms; Length: 0.8 meters; Breadth: $0.1 \mathrm{~m}$; and Height: 0.09 meters, while the ability to reach the depth of the dive is influenced by the flip angle and speed of the ship, the greater the speed and the angle of the flip, the greater the depth of diving that can be taken. The maximum depth that the submarine can reach is 0.94 meters with a vessel speed of $1 \mathrm{~m} / \mathrm{s}$ and a flip angle of $-30^{0}$.

\section{Acknowledgments}

Our gratitude goes to the LPPM of Hang Tuah University and Community RC Boat Model in Indonesia, especially Hang Tuah Model Boat (HTMB).

\section{Reference}

http://airfoiltools.com/airfoil/details?airfoil=naca1412-il

Joung, T-H., Sammut, K., He, F., and Lee, S-K., 2012. Shape Optimization of an Autonomous Underwater Vehicle with a Ducted Propeller Using Computational Fluid Dynamics Analysis. International Journal of Naval Architecture and Ocean Engineering, Volume 4, pp. 44-56.

Katz, J., 2010. Introduction Fluid Mechanics. Cambridge University Press, United State of America.

Munazid, A., and Suwasono, B., 2015. Foil Development of NACA Seri 2412 as Diving System of Submarine Model, Ship, 12(2), pp. 88-96.

Tupper., E.C., 2004. Introduction to Naval Architecture, $4^{\text {th }}$ Edition, Elsevier. 